\title{
Optimization of In-vivo Monitoring Program for Radiation Emergency Response
}

\author{
Wi-Ho Ha ${ }^{1,2, *}$, Jong Kyung Kim² \\ ${ }^{1}$ National Radiation Emergency Medical Center, Korea Institute of Radiological and Medical Sciences, Seoul, Korea; ${ }^{2}$ Department of Nuclear Engineering, \\ Hanyang University, Seoul, Korea
}

\section{Original Research}

Received July 17, 2015

Revision August 2, 2016

Accepted October 24, 2016

Corresponding author: Wi-Ho $\mathrm{Ha}$

National Radiation Emergency Medical Center, Korea Institute of Radiological and Medical, 75 Nowon-gil, Nowon-gu, Seoul 01812 , Korea

Tel: +82-2-970-1430, Fax: +82-2-970-1952

E-mail: lovin@kirams.re.kr

This is an Open-Access article distributed under the terms of the Creative Commons Attribution NonCommercial License (http://creativecommons.org/ licenses/by-nc/4.0) which permits unrestricted noncommercial use, distribution, and reproduction in any medium, provided the original work is properly cited.

Copyright $\odot 2016$ The Korean Association for Radiation Protection

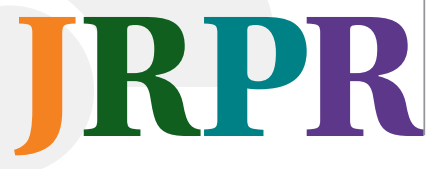

Background: In case of radiation emergencies, internal exposure monitoring for the members of public will be required to confirm internal contamination of each individual. In-vivo monitoring technique using portable gamma spectrometer can be easily applied for internal exposure monitoring in the vicinity of the on-site area.

Materials and Methods: In this study, minimum detectable doses (MDDs) for ${ }^{134} \mathrm{Cs},{ }^{137} \mathrm{Cs}$, and ${ }^{131} \mathrm{I}$ were calculated adjusting minimum detectable activities (MDAs) from 50 to $1,000 \mathrm{~Bq}$ to find out the optimal in-vivo counting condition. DCAL software was used to derive retention fraction of Cs and I isotopes in the whole body and thyroid, respectively. A minimum detectable level was determined to set committed effective dose of $0.1 \mathrm{mSv}$ for emergency response.

Results and Discussion: We found that $M D D$ s at each $M D A$ increased along with the elapsed time. $1,000 \mathrm{~Bq}$ for ${ }^{134} \mathrm{Cs}$ and ${ }^{137} \mathrm{Cs}$, and $100 \mathrm{~Bq}$ for ${ }^{131} \mathrm{I}$ were suggested as optimal MDAs to provide in-vivo monitoring service in case of radiation emergencies.

Conclusion: In-vivo monitoring program for emergency response should be designed to achieve the optimal $M D A$ suggested from the present work. We expect that a reduction of counting time compared with routine monitoring program can achieve the high throughput system in case of radiation emergencies.

Keywords: In-vivo monitoring, Internal exposure, Emergency response, Radiobioassay, Internal contamination

\section{Introduction}

Internal exposure for the members of public as well as radiation workers can be caused by accidental releasing of radioactive materials in nuclear and radiation accidents. These individuals will need to be quickly evaluated for radioactive contamination. Individual monitoring for the members of public is essential to confirm health effects of them in case of radiation emergencies. In general, whole body counting or urine bioassays are used for routine monitoring program of internal exposure of radiation workers. However, another less-sensitive method to assess internal contamination levels for a large number of people in a short period of time has to be taken into account in case of radiation emergencies such as nuclear accidents or Radiological Dispersal Device (RDD) event [1]. It would be desirable to use a simple method to rapidly screen individuals in the field. The initial field screening can help identify individuals who are highly contaminated and prioritize ones for further evaluation and more de- 
finitive treatment [1].

In-vivo monitoring technique using portable gamma spectrometer can be applied for internal exposure monitoring in the field because portable detectors can be easily transported to the on-site area and do not require assembly. Therefore, in-vivo monitoring program has to be optimized to be properly used at the on-site area for the purpose of radiation emergency response.

The objective of this study is to derive minimum detectable doses $(M D D s)$ along with minimum detectable activity (MDA) using the dosimetric information of ${ }^{134} \mathrm{Cs},{ }^{137} \mathrm{Cs}$, and ${ }^{131} \mathrm{I}$ which are representative gamma-emitting radionuclides causing internal exposure of the members of public following nuclear and radiation accidents. And we suggested the optimal MDA and monitoring period for in-vivo monitoring of ${ }^{134} \mathrm{Cs},{ }^{137} \mathrm{Cs}$, and ${ }^{131} \mathrm{I}$ following such accidents and optimized in-vivo monitoring program using portable NaI gamma spectrometer to be applied for radiation emergency response.

\section{Materials and Methods}

\section{General MDAs of the concerned radionuclides}

$M D A$ is one of the important parameters to represent the performance of the radiation measurement system. The $M D A$ is determined by the counting efficiency, counting time, emission yield, and net count level of blank sample in the region of interest (ROI). In routine radiobioassay program, typical and achievable $M D A s$ were provided from IDEAS guideline (General guidelines for the estimation of committed ef- fective dose from incorporation monitoring data) reported by the EURADOS [2]. In this study, we selected the concerned radionucldies which can be released to the environments and cause internal exposure of general public as well as radiation workers in case of radiation accidents. ${ }^{134} \mathrm{Cs}$, ${ }^{137} \mathrm{Cs}$, and ${ }^{131} \mathrm{I}$ were determined as the concerned radionuclides in the present work. American National Standard Institute (ANSI) also suggested the MDAs for direct radiobioassay, also known as in-vivo measurement, to be applied for routine monitoring program of internal exposure [3]. The MDAs selected from ANSI are relatively higher than those provided by EURADOS. The MDAs of these radionuclides for the in-vivo measurement are summarized in Table 1.

\section{Calculation of MDDs along with the MDAs}

$M D D s$ for ${ }^{134} \mathrm{Cs},{ }^{137} \mathrm{Cs}$, and ${ }^{131}$ I were calculated adjusting MDAs from 50 to 1,000 Bq to find out the optimal in-vivo monitoring condition. In general, committed effective dose (CED) can be calculated as following simple equation:

$$
C E D=\text { Intake } \times D C C=\frac{M}{m(t)} \times D C C
$$

where, $D C C$ is dose conversion coefficient $\left[\mathrm{Sv} \cdot \mathrm{Bq}^{-1}\right], M$ is measurement quantities of in-vivo monitoring $[\mathrm{Bq}]$, and $m(t)$ is bioassay function representing retention fraction as a function of time $t$ after intake [Bq.Bq-intake ${ }^{-1}$. Then $M D D$ can be derived as below:

$$
M D D=\frac{M D A}{m(t)} \times D C C
$$

Table 1. MDAs of the Concerned Radionuclides in the Routine Monitoring Program

\begin{tabular}{llccc}
\hline \multirow{2}{*}{ Radionuclides } & Monitoring method & MDAs $(\mathrm{Bq})$ from IDEAS Guideline Ver. 2 (2013) & \multirow{2}{*}{$\begin{array}{c}\text { MDAs (Bq) from ANSI/HPS } \\
\text { N13.30 (1996) }\end{array}$} \\
\cline { 3 - 4 } & & Typical MDA & Achievable MDA & 755 \\
\hline${ }^{134} \mathrm{Cs}$ & Whole body monitoring & 40 & 10 & 870 \\
${ }^{137} \mathrm{Cs}$ & Whole body monitoring & 60 & 15 & 902 \\
\hline${ }^{131} \mid$ & Thyroid monitoring & 25 & 1 & 902 \\
\hline
\end{tabular}

\begin{tabular}{|c|c|c|c|c|c|}
\hline \multirow[t]{2}{*}{ Radionuclides } & \multirow[t]{2}{*}{ Absorption type } & \multirow[t]{2}{*}{$A M A D(\mu \mathrm{m})$} & \multirow[t]{2}{*}{$f_{1}^{*}$} & \multicolumn{2}{|c|}{$\begin{array}{c}\text { Dose Conversion Coefficients }\left(\mathrm{Sv} \cdot \mathrm{Bq}^{-1} \text { ) from }\right. \\
\text { ICRP Pub. } 72 \text { (1996) }\end{array}$} \\
\hline & & & & 10-yr old & Adult \\
\hline${ }^{134} \mathrm{Cs}$ & Fast & 1 & 1.0 & 5.3E-09 & 6.6E-09 \\
\hline${ }^{137} \mathrm{Cs}$ & Fast & 1 & 1.0 & 3.7E-09 & 4.6E-09 \\
\hline${ }^{131} \mid$ & Fast & 1 & 1.0 & 1.9E-08 & 7.4E-09 \\
\hline
\end{tabular}

Table 2. Biokinetic and Dosimetric Parameters of the Concerned Radionuclides for Calculation of the MDDs

AMAD, Activity Median Aerodynamic Diameter.

${ }^{\star} f_{1}$ : Factional absorption in the gastrointestinal tract. 
In this study, we used DCAL software [4], which was developed at the Oak Ridge National Laboratory, to obtain the bioassay function of ${ }^{134} \mathrm{Cs}$ and ${ }^{137} \mathrm{Cs}$ in the whole body and ${ }^{131} \mathrm{I}$ in the thyroid. Elapsed time after initial intake was considered for $365 \mathrm{~d}$ when we calculated the retention fraction of each radionuclide. DCCs of the members of public were used from ICRP 72 [5] in which age-dependent dose coeffi-
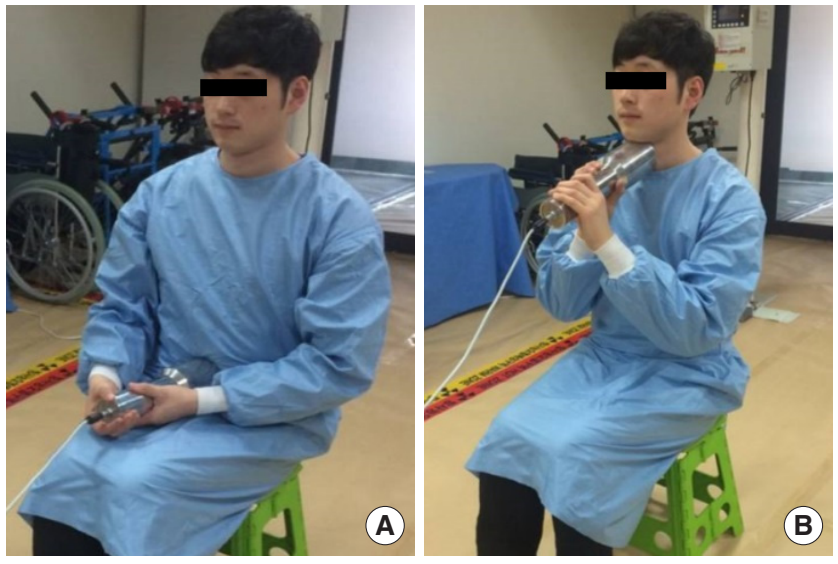

Fig. 1. Counting geometries for in-vivo monitoring: (A) Whole body counting and (B) Thyroid monitoring. cients were provided from intake of radionuclides. Only inhalation was employed as a pathway of intake of the concerned radionuclides. And 10-yr old child and adult were used as age group of the public in this calculation. Table 2 shows the biokinetic parameters and DCCs used in this study. In order to find out the optimal MDA level for emergency response, $M D D s$ were calculated adjusting $M D A s$ from 50 to $1,000 \mathrm{~Bq}$.

\section{Evaluation of $M D A$ using portable in-vivo counter}

We used portable $3 \times 3$ inch NaI gamma spectrometer (RIIDEYE-M-G3, Thermo, Waltham, MA) to quantify the $M D A$ of ${ }^{134} \mathrm{Cs}$, ${ }^{137} \mathrm{Cs}$ and ${ }^{131} \mathrm{I}$. Counting geometries shown in Figure 1 were applied to measure radioactivity retained in whole body and thyroid, respectively. And we used BOMAB (Bottle Manikin Absorption) phantom [6] and IAEA/ANSI neck phantom [7] including mixed gamma-emitting radionuclides as a certified reference material (CRM) for the calibration of two counting geometries, whole body counting and thyroid monitoring, respectively. Counting time was employed to be $60,120,240$ s for each counting geometry. We
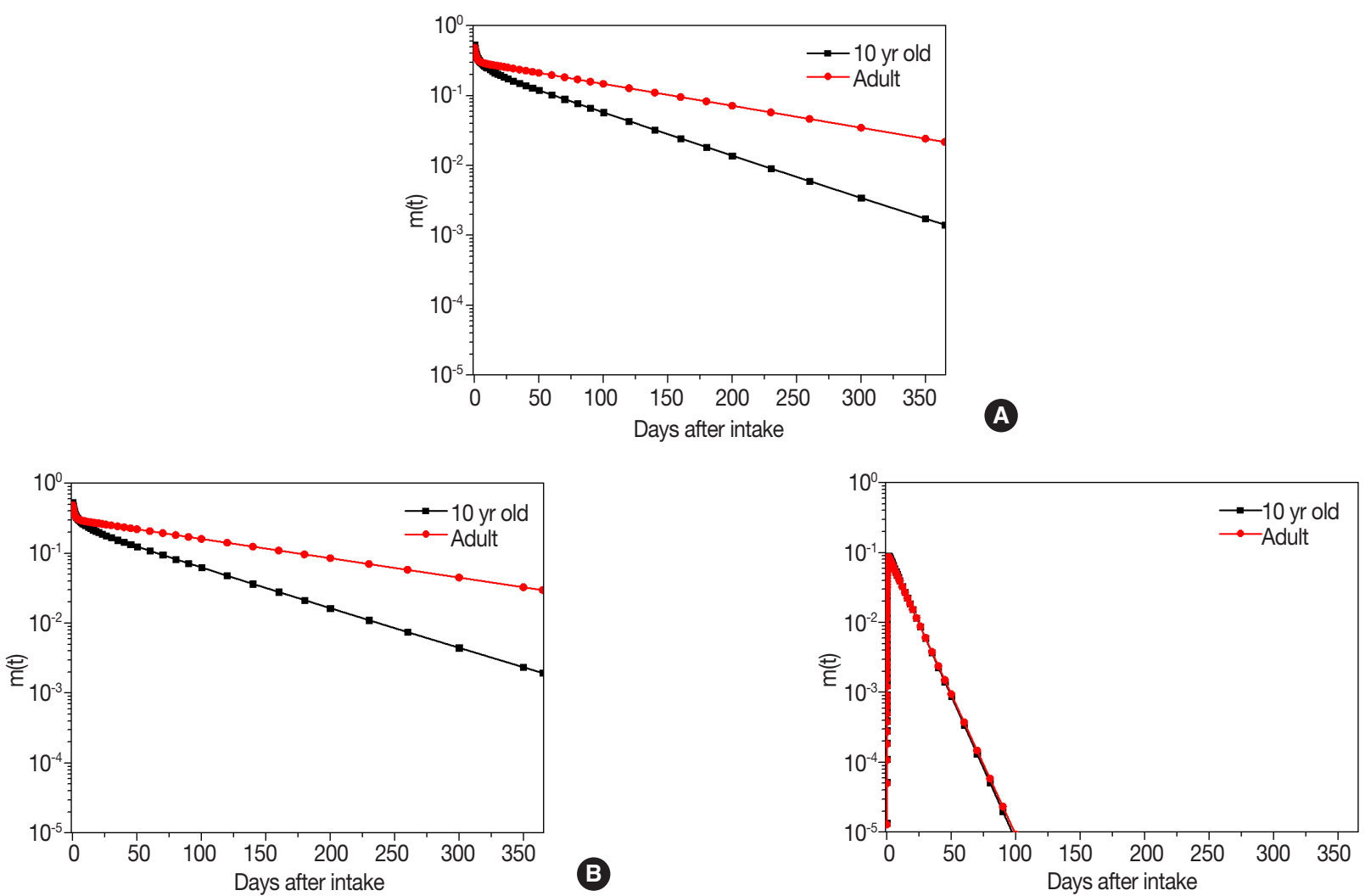

Fig. 2. Bioassay functions of concerned radionuclides: (A) Total body retention fraction of ${ }^{134} \mathrm{Cs}$, (B) Total body retention fraction of ${ }^{137} \mathrm{Cs}$, and (C) Thyroid retention fraction of ${ }^{131}$. 
repeatedly measured the activity of the blank sample 5 times for each counting time and evaluated the averaged $M D A$ of ${ }^{134} \mathrm{Cs}$, ${ }^{137} \mathrm{Cs}$, and ${ }^{131} \mathrm{I}$ depending on the counting time. After

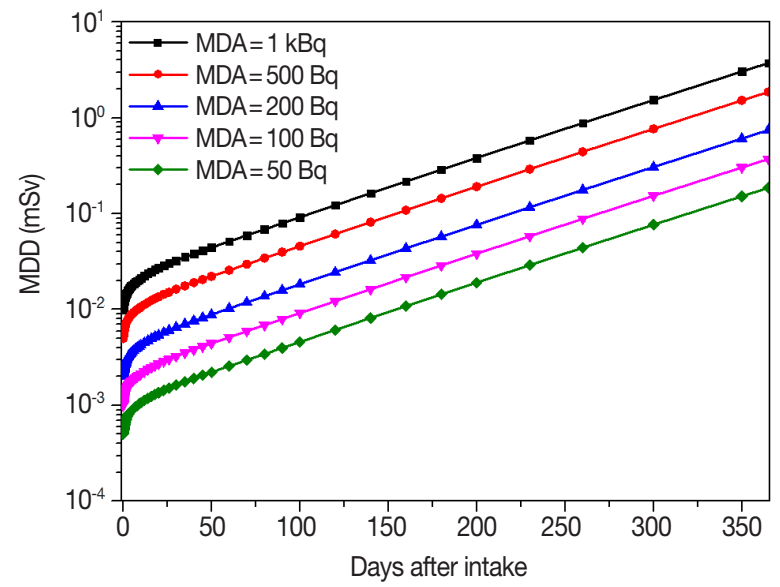

A that, we compared the evaluated $M D A$ with the suggested optimal MDAs to test the acceptance of the optimal $M D A$.

Fig. 3. MDD depending on the age and MDA for ${ }^{134} \mathrm{Cs}$ : (A) 10-yr old child and (B) adult.
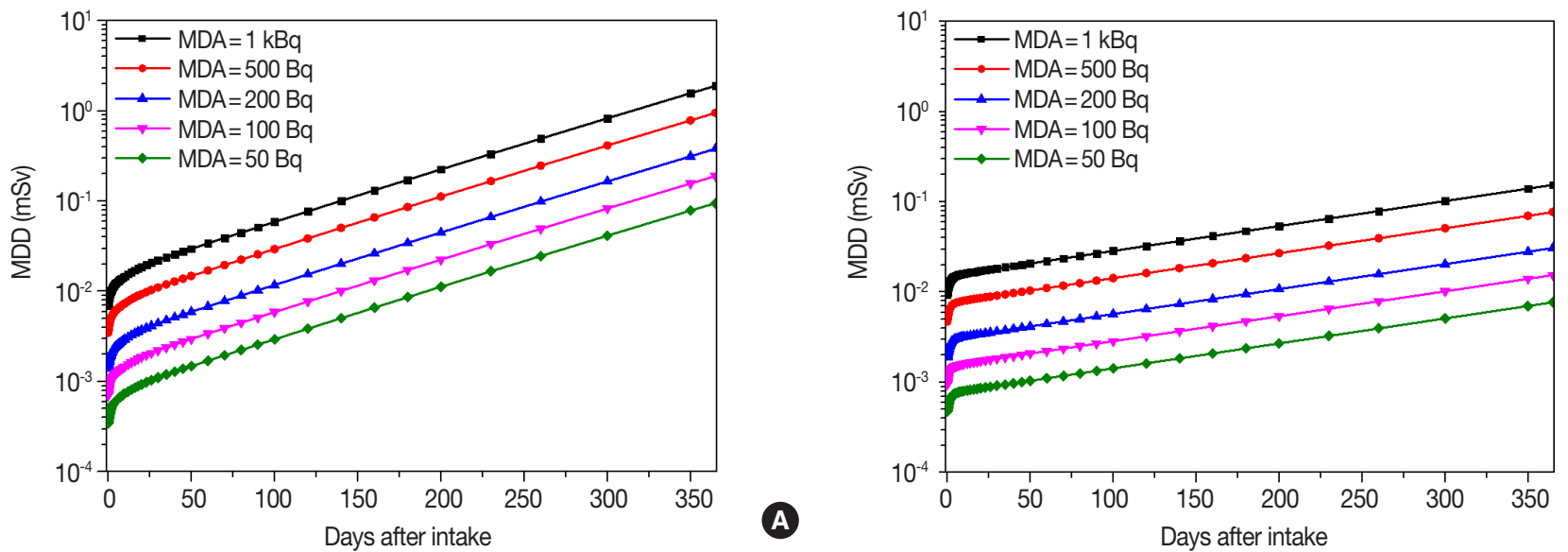

Fig. 4. MDD depending on the age and $M D A$ for ${ }^{137} \mathrm{Cs}$ : (A) 10-yr old child and (B) adult.
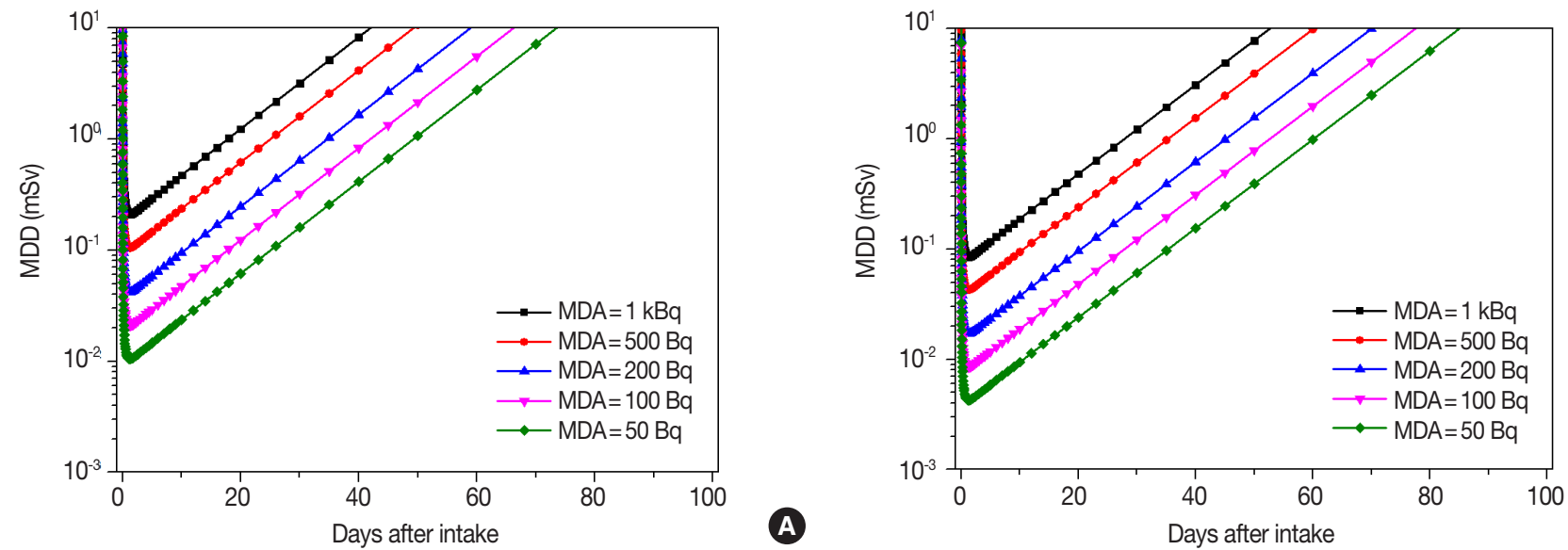

B

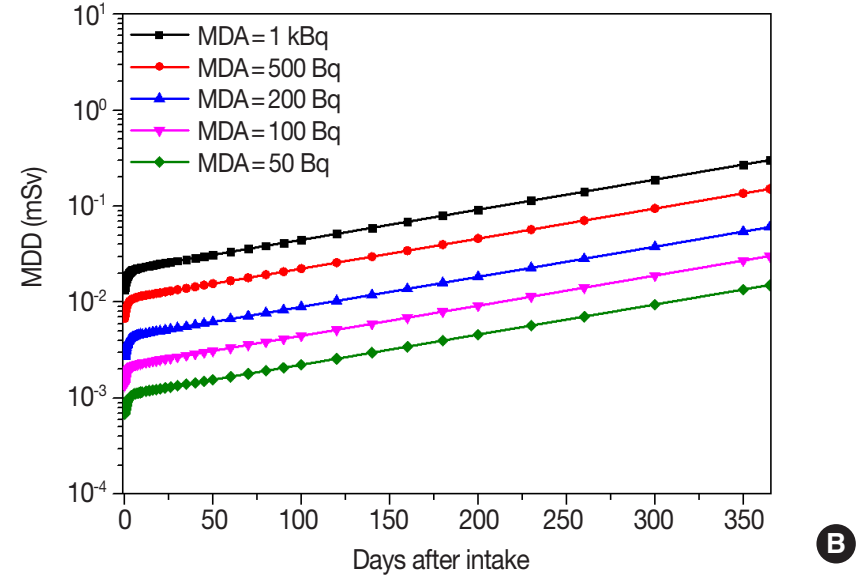

\section{A}

B

Fig. 5. MDD depending on the age and MDA for ${ }^{131}$ : (A) 10-yr old child and (B) adult. 


\section{Results and Discussion}

\section{Derived bioassay functions and $M D D s$}

Bioassay functions, $m(t)$, as the retention fraction for 365 day after initial intake were calculated using the DCAL software. Figure 2 shows bioassay functions of 10-yr old child and adult for ${ }^{134} \mathrm{Cs}$, ${ }^{137} \mathrm{Cs}$, and ${ }^{131} \mathrm{I}$. Bioassay functions during the elapsed period showed the similar pattern between ${ }^{134} \mathrm{Cs}$ and ${ }^{137} \mathrm{Cs}$ since the biokinetic model and chemical properties are almost same for Cs isotopes. From the calculation results of Cs isotopes, we verified that retention fraction of $10-\mathrm{yr}$ old child decreased more rapidly than adult. On the other hand, bioassay function in the thyroid for ${ }^{131}$ I showed the different pattern with Cs isotopes. Retention fraction in the thyroid did not have a significant difference between 10-yr old child and adult. The faction in the thyroid showed the high peak around $1.2 \mathrm{~d}$ after intake and very sharply decreased to $10^{-5}$ within $100 \mathrm{~d}$.

Figures 3 to 5 show the $M D D s$ depending on the age and the $M D A s$ for ${ }^{134} \mathrm{Cs},{ }^{137} \mathrm{Cs}$, and ${ }^{131} \mathrm{I}$. MDDs of ${ }^{134} \mathrm{Cs}$ were slightly higher than those of ${ }^{137} \mathrm{Cs}$ for each age group. Even though their bioassay functions showed the similar pattern, MDDs of ${ }^{134} \mathrm{Cs}$ were 1.48 times higher than those of ${ }^{137} \mathrm{Cs}$ since the DCCs of ${ }^{134} \mathrm{Cs}$ are higher than those of ${ }^{137} \mathrm{Cs}$.

We found that $M D D s$ increased not only when the elapsed time passed after the initial intake of the concerned radionuclides but also while the MDAs increased from 50 to 1,000 Bq. In case of ${ }^{137} \mathrm{Cs}, M D D$ s for 10 -yr old child increased more rapidly than adult because the retention fraction for $10-\mathrm{yr}$ old child showed to be decreased more rapidly after the intake. In case of ${ }^{131} \mathrm{I}, \mathrm{MDD}$ for 10 -yr old child were 2.73 times higher than adult since the DCCs of ${ }^{131}$ I for child are higher than adult.

\section{Optimized in-vivo monitoring program}

ICRP 103 recommended that reference levels for the highest planned residual doses in emergency situations are typically in the $20 \mathrm{mSv}$ to $100 \mathrm{mSv}$ band of projected doses [8].

Table 3. Optimal MDA and Monitoring Period of In-vivo Monitoring Program for Radiation Emergency Response

\begin{tabular}{llcc}
\hline Radionuclides & \multicolumn{1}{c}{$\begin{array}{c}\text { Monitoring } \\
\text { Method }\end{array}$} & $\begin{array}{c}\text { Optimal MDA } \\
(\mathrm{Bq})\end{array}$ & $\begin{array}{c}\text { Optimal Moni- } \\
\text { toring Period } \\
\text { (day) }\end{array}$ \\
\hline${ }^{134} \mathrm{Cs}$ & Whole body monitoring & $\leq 1,000$ & $\leq 100$ \\
${ }^{137} \mathrm{Cs}$ & Whole body monitoring & $\leq 1,000$ & $\leq 130$ \\
${ }^{131} \mathrm{I}$ & Thyroid monitoring & $\leq 100$ & $\leq 20$ \\
\hline
\end{tabular}

However, these levels are relatively higher than dose limit $\left(=1 \mathrm{mSv}^{-1}\right)$ of the public in planned exposure situations. In addition, Occupational Intake of Radionuclides (OIR) report issued by ICRP suggested that common practice of individual monitoring for workers whose internal dose from annual intakes could exceed $1 \mathrm{mSv}$ should be done [9]. In this study, in order to provide rapid screening of internal exposure in case of radiation emergencies, a minimum detectable level was determined to set committed effective dose of $0.1 \mathrm{mSv}$ which is 10 times lower than dose limit of the public corresponding with dose level in which practice of individual monitoring for workers is required.

We suggested the optimal MDAs and monitoring period summarized in Table 3 to perform the individual monitoring. $1,000 \mathrm{~Bq}$ for ${ }^{134} \mathrm{Cs}$ and ${ }^{137} \mathrm{Cs}$, and $100 \mathrm{~Bq}$ for ${ }^{131} \mathrm{I}$ were suggested as the optimal MDAs in case of radiation emergencies. And the optimal monitoring period of ${ }^{134} \mathrm{Cs}$ and ${ }^{137} \mathrm{Cs}$ was within $100 \mathrm{~d}$ and $130 \mathrm{~d}$, respectively, after the event causing internal exposure, and the monitoring period of ${ }^{131} \mathrm{I}$ was within around $20 \mathrm{~d}$ after the event to detect internal exposure below $0.1 \mathrm{mSv}$. These optimal levels were derived on the basis of dose levels for 10-yr old child because these levels were more conservative than those derived from adult. Moreover, we can extend the monitoring period to provide in-vivo monitoring services for adult since the MDDs for adult were lower than those for 10-yr old child.

\section{Discussions on the optimized monitoring condition}

Figure 6 shows $M D A s$ of ${ }^{134} \mathrm{Cs},{ }^{137} \mathrm{Cs}$, and ${ }^{131}$ I measured using portable $\mathrm{NaI}$ gamma spectrometer. The optimal MDAs were achievable when counting time was $120 \mathrm{~s}$ for ${ }^{137} \mathrm{Cs}$ and

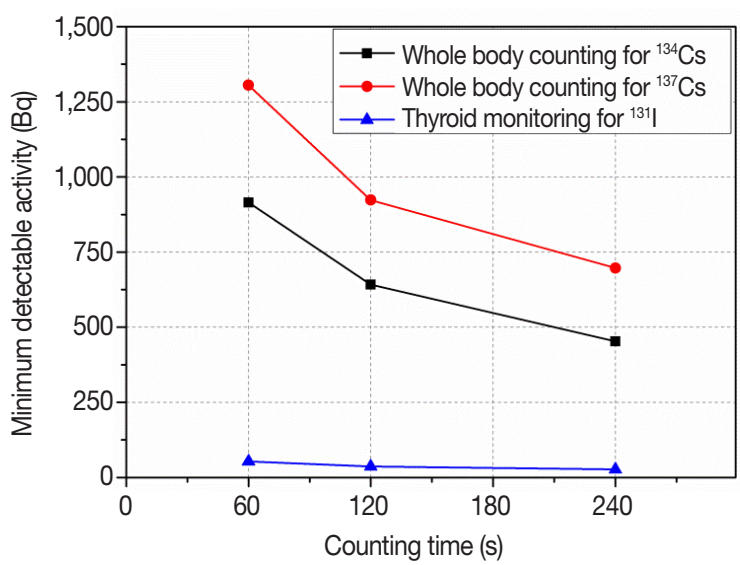

Fig. 6. MDA of the concerned radionuclides according to counting time. 
$60 \mathrm{~s}$ for ${ }^{134} \mathrm{Cs}$ and ${ }^{131} \mathrm{I}$. However, the optimal MDAs were determined based on the committed effective dose of $0.1 \mathrm{mSv}$ in this work. The optimal MDAs could be adjusted by dose level which we applied as a minimum detectable level in case of radiation emergencies. When we determine higher $M D D$ as a detectable level for emergency response, $M D A s$ could be increased more than the suggested optimal MDAs. Furthermore, we need to consider the increased background level which can cause an increase of $M D A s$ of the concerned radionuclides in case of radiation emergencies.

The optimal monitoring period is also dependent on the $M D D$, the age group of monitoring subjects, and the type of radionuclide. For ${ }^{134} \mathrm{Cs},{ }^{137} \mathrm{Cs}$, and ${ }^{131} \mathrm{I}$, we found that the optimal monitoring period will be extended when the higher MDDs were applied for in-vivo monitoring. And adult agegroup showed longer monitoring period than 10 -yr old child for the concerned radionuclides in this work.

In addition, only 10-yr old child and adult were considered to represent the member of public in this work. Taking account of other age-groups would be necessary to apply in-vivo monitoring program for the member of public covering all age-groups. And this study only covers in-vivo monitoring for gamma-emitting radionuclides such as Cs and I isotopes. On the other hand, in case of suspected internal exposure for alpha- or beta-emitting radionuclides, the other monitoring method such as in-vitro radiobioassay should be applied to identify and quantify these radionuclides. And the other portable gamma spectrometers can be used instead of NaI detector even though NaI detectors are widely used as a portable gamma spectrometer.

\section{Conclusion}

In this study, we derived $M D D s$ along with $M D A$ using the dosimetric information of ${ }^{134} \mathrm{Cs},{ }^{137} \mathrm{Cs}$, and ${ }^{131} \mathrm{I}$ which are representative gamma-emitting radionuclides causing internal exposure of the members of public in case of radiation emergencies. Moreover, we suggested the optimal in-vivo monitoring program to be applied for radiation emergency response.

We expect that even though a reduction of counting time compared with routine monitoring usually causes the increase of MDAs of in-vivo monitoring system, it can achieve the high throughput system in case of radiation emergencies. Therefore, in-vivo monitoring program for emergency response should be designed to obtain the optimal MDAs suggested in this study. To apply this optimal in-vivo monitoring condition for rapid screening of general public, we need to perform more studies on the performance test of various types of portable gamma spectrometer such as HPGe or CZT detector and their efficiency calibration considering the posture and size of human body in the near future. In addition, detectable dose level of $0.1 \mathrm{mSv}$ to be applied for emergency exposure situation can be adjusted considering various parameters such as benefits from radiation exposure, public acceptance and national regulatory guide.

\section{Acknowledgements}

This study was supported by a grant of the Korea Institute of Radiological and Medical Sciences (KIRAMS), funded by Ministry of Science, ICT and Future Planning, Republic of Korea (1711031804/50445-2016).

\section{References}

1. Manger RP, Hertel NE, Burgett EA, Ansari A. Using handheld plastic scintillator detectors to triage individuals exposed to a radiological dispersal device. Radiat. Prot. Dosim. 2011 Nov;150 (1):101-108.

2. Castellani CM, Marsh JW, Hurtgen C, Blanchardon E, Berard P, Giussani A, Lopez MA. IDEAS guidelines (Version 2) for the estimation of committed doses from incorporation monitoring data. EURADOS-2013-01. 2013;27-29.

3. American National Standard Institute. Performance criteria for radiobioassay. ANSI/HPS N13.30. 1996;105-106.

4. Oak Ridge National Laboratory. User's guide to the DCAL system. ORNL/TM-2001/190. 2006;24-30.

5. International Commission of Radiological Protection. Age-dependent doses to members of the public from intake of radionuclides: Part 5 compilation of ingestion and inhalation dose coefficients. ICRP Publication 72. 1996;26(1):61-62.

6. American National Standard Institute. Specifications for the bottle manikin absorption phantom. ANSI/HPS N13.35. 1999;1213.

7. American National Standard Institute. Thyroid phantom used in occupational monitoring. ANSI/HPS N13.44. 2014;3-4.

8. International Commission of Radiological Protection. The 2007 recommendations of the international commission on radiological protection. ICRP Publication 103. 2007;37(2-4):108-110.

9. International Commission of Radiological Protection. Occupational intakes of radionuclides: Part 1. ICRP Publication 130. 2015; 44(2):53-54. 